\title{
Overweight Proxies Are Associated with Atopic Asthma: A Matched Case-Control Study
}

\author{
Manuela Gramss ${ }^{a, b}$ Tobias Lipek ${ }^{a, b}$, e Mandy Vogel ${ }^{a, b} \quad$ Johannes Remmler ${ }^{c}$ \\ Andreas Hiemisch $^{a, b}$ Anne Jurkutat ${ }^{b}$ Jon Genuneit ${ }^{a, d}$ Antje Körner ${ }^{a, b}$, e Wieland Kiess ${ }^{a, b}$ \\ ${ }^{a}$ Hospital for Children and Adolescents, Centre for Paediatric Research Leipzig, University Hospitals, Leipzig \\ University, Leipzig, Germany; ${ }^{b}$ LIFE, Leipzig Research Center for Civilization Diseases, Leipzig University, Leipzig, \\ Germany; ' Institute of Laboratory Medicine, Clinical Chemistry and Molecular Diagnostics, University Hospitals, \\ Leipzig University, Leipzig, Germany; ${ }^{\mathrm{I}}$ Institute of Epidemiology and Medical Biometry, Ulm University, Ulm,

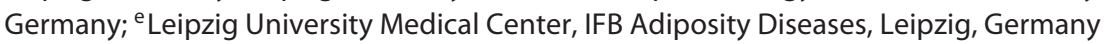

\section{Keywords}

Asthma · Atopy · Children · LIFE Child · Overweight

\begin{abstract}
Background: Many studies have documented a link between overweight and asthma in children with contradictory results regarding the best way to measure overweight. Moreover, often, the dynamic development of atopy, overweight, and asthma is controlled for age dependency insufficiently. Objective: This study assesses and compares the associations of overweight measured as waist circumference, waist to height ratio (WHtR), neck circumference, and body mass index with the occurrence of asthma - best possibly controlling for age-dependencies of these parameters. Methods: From a sample of 2,511 children aged 6-17 years, we matched 157 children with asthma with 2 controls ( $n=$ 471 ) according to age and atopy status and performed conditional logistic regression analyses. We further investigated the role of known influencing factors of asthma occurrence. Results: In children with atopy, all overweight proxies were consistently positively associated with asthma. Statistical significance was reached for WHtR-SD score (OR 1.26, 95\% Cl $1.03-1.54, p=0.025$ ) and persisted when further covariates, such as birth weight or social status, were added to the model. Groups of atopic versus nonatopic participants do not dif-
\end{abstract}

\section{KARGER}

(c) 2019 S. Karger AG, Basel

E-Mail karger@karger.com

www.karger.com/hrp fer in levels of interleukin-6 or high-sensitivity C-reactive protein. Conclusion: In our cohort, overweight seems to carry a risk for asthma only if accompanied with atopy. We call for more strict age matching in pediatric cohort studies and longitudinal studies for a better understanding for causal links of overweight, atopy, and asthma.

(c) 2019 S. Karger AG, Basel

\section{Introduction}

Anthropometric measurements are essential and regularly applied tools for physicians, especially in child care. As asthma is one of the most prevalent diseases in childhood [1], it seemed compelling to predict asthma severity better by additional measurements of waist or neck circumference (WC, NC) as suggested by results of earlier studies $[2,3]$. Usually, overweight is measured in body mass index (BMI) and was shown to be associated with asthma in a multitude of studies [4], even though usage as a proxy for overweight remains disputed [5]. Anthropometry seems promising in discriminating individuals with overweight, also given that asthma therapy

M.G. and T.L. contributed equally to this work. 
stratified by weight status (based on BMI) yielded conflicting results [6-8].

Studies on the association of overweight, atopic diseases, and asthma do acknowledge age dependency of the overweight and asthma incidences, but only controlled for a linear effect of age in multivariable analyses $[9,10]$, which might be a too strong statistical assumption. Forno et al. [11] report inverse relationships in the interplay of asthma, adiposity, and atopy for different age groups (819 vs. 20-69 years of age) also pointing out the significance of age while exploring the association of adiposity and asthma in atopic versus nonatopic study subjects. As a recent review stresses the importance of controlling for age and interdependent variables, it is not surprising that even the currently much discussed subtype of obese-asth$\mathrm{ma}$ is said to differ in phenotypes between children and adults $[12,13]$. In a recent cohort study of children, all aged 6 years, objective information on atopy status to distinguish participants with overweight and asthma was not available [14].

We thus sought to examine whether children with overweight are at a higher risk of asthma in our cohort study, aiming for the best possible exclusion of age-dependency in a matched case-control analysis.

\section{Materials and Methods}

\section{Study Design and Setting}

We assessed data originating from the ongoing LIFE Child cohort study that started in January 2011. We included children aged 6-16 years providing information on medical history, anthropometric data, and medication use. Children aged $<6$ years were not included in the analysis because asthma diagnosis in these children usually is less clear-cut and, hence, less reliable [1]. Finally, 2,511 children with a total of 7,054 visits between January 2011 and June 2018 were included (primary sample).

\section{Assessments}

Medical history of participants was assessed through computer-assisted personal interviews. Current medication was assessed during an interview by obtaining a National Drug Code and its subsequent classification based on the Anatomical Therapeutic Chemical Classification System. If the accurate classification was not possible during the interview, information was obtained in a subsequent telephone-based interview [15].

\section{Anthropometry}

Height was measured to the nearest of $0.1 \mathrm{~cm}$ using a stadiometer ("Dr. Keller” Längenmesstechnik, Germany), and weight was quantified by a digital balance to the nearest of $100 \mathrm{~g}$. NC and WC were measured in a standardized procedure using a measuring tape. Waist-to-height-ratio (WHtR) and BMI were calculated. Due to the lack of published reference values comprising the whole age span and to account for possible regional differences, NC, WC, and
WHtR measures were standardized for age and sex using the "LMS" method by Cole and Green [16] utilizing the entire LIFE Child cohort, as performed previously [17, 18]. For BMI, German reference values were used as recommended by current German guidelines on diagnosis and treatment of overweight in children [19].

\section{Laboratory Markers}

Venous blood samples (serum and ethylenediaminetetraacetic acid whole blood) were taken at the beginning of each survey day in weight and age-appropriate containers (Sarstedt, Germany). Specific immunoglobulin E inhalation screen (SX1) was determined with a fluorescence enzyme immunoassay using the CAP250 Phadia system (Thermo Fisher Scientific, Waltham, MA, USA). SX1-kit tests for sensitizations to timothy, rye, birch, mugwort, cat dandruff, dog dandruff, house dust mite, and Cladosporium herbarum by quantifying specific IgE. According to previous studies [11,20,21], atopy was defined by exceeding the predefined cutoff in SX1, <0.35 kU/L. High-sensitivity C-reactive protein (hsCRP) was measured using a turbidimetric immunoassay (with a cutoff $<5 \mathrm{mg} / \mathrm{L}$ ), and interleukin-6 (IL-6) was measured using an electro-chemiluminescence immunoassay (with a cutoff $<4.25 \mathrm{pg} / \mathrm{mL}$ ), both performed on the cobas 8000 analyzer (Roche Diagnostics, Switzerland). Reasons for missing values were nonconsent to blood sampling in children or incomplete or unsuccessfully blood withdrawals. A more detailed description of the LIFE Child study is provided elsewhere [22, 23].

\section{Defining Patients with Asthma}

According to previous cohort study criteria [24,25], the operational definition of asthma was based on matching 2 of the following 3 criteria: (i) doctor's diagnosis of asthma ever, (ii) prescribed medication for asthma treatment, and (iii) wheezing in the last 12 months according to "The International Study of Asthma and Allergies in Childhood" parental or self-reported core questionnaire [26]. Since yearly follow-up visits were available, children were classified as asthma cases on the first visit they fulfilled diagnostic criteria (t1). Age, anthropometric data, hsCRP, and IL-6 - values at $t 1$ were chosen for analyses. If no SX1 values were available at $\mathrm{t} 1$, information on atopy status was taken from prior SX1-screenings, if available. Children exceeding SX1-cutoff at least once were classified as atopic subjects.

\section{Case-Control Selection}

For each participant with asthma, we matched controls by age and atopy at $\mathrm{t} 1$ applying the algorithm proposed by Ho et al. [27], minimizing average absolute distance across all matched pairs as suggested before [28]. Because of the known impact on asthma of atopy status, we aimed to include atopy as a matching criterion. Missing values in SX1-screening lead to a reduction of the number of cases to 157 (75\% of cases). Case-to-control ratio was set to 1:2 because we aimed for the best possible age matches and increasing the numbers of controls would have resulted in disproportionate dilution. A 1:2 matching achieved a mean absolute age difference between cases and controls of 0.00875 years $(p=0.975)$. For 4 cases, one of the 2 control participants exceeded 0.5 years of age difference $(0.98,0.90,0.63$, and 0.55 years). Every study subject was included only once in the analyses.

\section{Covariates}

The following additional possible confounders of the overweight-asthma link were considered: physical activity measured as 
Table 1. Univariate analysis of confounding variables, total sample

\begin{tabular}{lccr}
\hline Total (primary) sample & $\begin{array}{r}\text { Asthma no } \\
(n=1,985)\end{array}$ & $\begin{array}{l}\text { Asthma yes } \\
(n=208)\end{array}$ & p.overall \\
\hline Age at t1, years & $12.5(3.15)$ & $10.9(2.92)$ & $<0.001$ \\
Gender & & & 0.019 \\
$\quad$ Male & $989(49.8)$ & $122(58.7)$ & \\
$\quad$ Female & $996(50.2)$ & $86(41.3)$ & \\
Atopy & & & $<0.001$ \\
$\quad$ No & $966(58.0)$ & $35(22.3)$ & \\
$\quad$ Yes & $700(42.0)$ & $122(77.7)$ & \\
BMI-SDS at t1 & $0.34(1.30)$ & $0.39(1.27)$ & 0.630 \\
WC-SDS at t1 & $0.07(1.00)$ & $0.16(1.01)$ & 0.216 \\
NC-SDS at t1 & $0.12(0.99)$ & $0.06(1.01)$ & 0.442 \\
WHtR-SDS at t1 & $0.27(1.18)$ & $0.42(1.16)$ & 0.076 \\
Pubertal status & & & $<0.001$ \\
1 & $509(35.6)$ & $87(54.4)$ & \\
2 & $209(14.6)$ & $34(21.2)$ & \\
3 & $139(9.72)$ & $15(9.38)$ & \\
4 & $186(13.0)$ & $10(6.25)$ & \\
5 & $387(27.1)$ & $14(8.75)$ & \\
\hline
\end{tabular}
(SD).

Data displayed as frequency number (percentage) or mean

BMI, body mass index; NC, neck circumference; p.overall, significance level of $\alpha=0.05$; SDS, SD score; WC, waist circumference; WHtR, waistto-height ratio.

Table 2. Univariate analysis of confounding variables in 1:2 matched pair sample

\begin{tabular}{lrrr}
\hline Matched sample & $\begin{array}{l}\text { Asthma no } \\
(n=314)\end{array}$ & $\begin{array}{l}\text { Asthma yes } \\
(n=157)\end{array}$ & p.overall \\
\hline Age at t1, years & $11.1(2.90)$ & $11.1(2.90)$ & 0.975 \\
Gender & $172(54.8)$ & $88(56.1)$ & \\
$\quad$ Male & $142(45.2)$ & $69(43.9)$ & \\
$\quad$ Female & $70(22.3)$ & $35(22.3)$ & \\
Atopy & $244(77.7)$ & $122(77.7)$ & \\
$\quad$ No & $0.17(1.24)$ & $0.33(1.23)$ & 0.188 \\
$\quad$ Yes & $-0.02(1.01)$ & $0.11(0.99)$ & 0.190 \\
BMI-SDS at t1 & $0.02(1.02)$ & $0.04(0.98)$ & 0.899 \\
WC-SDS at t1 & $0.16(1.17)$ & $0.36(1.15)$ & 0.084 \\
NC-SDS at t1 & & & 0.565 \\
WHtR-SDS at t1 & $127(54.0)$ & $65(53.3)$ & \\
Pubertal status & $41(17.4)$ & $28(23.0)$ & \\
1 & $28(11.9)$ & $9(7.38)$ & \\
2 & $14(5.96)$ & $8(6.56)$ & \\
3 & $25(10.6)$ & $12(9.84)$ & \\
4 & &
\end{tabular}

Data displayed as frequency number (percentage) or mean (SD). Sums not adding to $n=471$ per row due to missing values.

$\mathrm{BMI}$, body mass index; NC, neck circumference; p.overall, significance level of $\alpha=0.05$; SDS, SD score; WC, waist circumference; WHtR, waistto-height ratio. physically active in a sports club at least once a week (parental and/ or children's report); having been breastfed for at least 6 months (parental report); active smoking (parental and/or children's report: "Does your child smoke?," "Have you ever smoked?"); passive smoking (parental report, "Has anyone smoked in the flat during the last 12 month?”); parental history of asthma (parental report, defined by information of mother and/or father); the socioeconomic status measured by means of the adjusted Winkler Index [29], combining information of the monthly household income, parents' education and occupation, and birth weight (low birth weight defined as $<2,500 \mathrm{~g}$, documented in a medical checkup booklet, which is used by the family's pediatrician to document the child's development and was scanned at each visit) and pubertal status according to Tanner stages [30]. Characteristics of the whole study population and the subgroup included in the casecontrol analyses are depicted in Tables 1 and 2. Inclusion criteria for the primary sample were children aged $>6$ and $<17$ years who participated at the LIFE Child cohort study from January 2011 to June 2018. Exclusion criteria were missing information about sex, age, WC, NC, BMI, WHtR, and multiple visits. Additionally, for the 1:2 matched sample subjects with missing information about asthma and atopy were excluded. Subjects with an age difference $>6$ months (except 4 cases) between cases and controls were also excluded as previously described. For detail, see Figure 1.

\section{Statistical Analyses}

For comparisons of the distribution of categorical variables, absolute and relative frequencies were calculated and chi-square tests were applied; for continuous variables (BMI, NC, WC, WHtR), $t$ tests were applied. Based on the matched sample, we applied conditional logistic regression to estimate the ORs and the respective CIs of developing asthma. Conditional logistic regression was chosen because we aimed for the best possible exclusion of age-dependency effects. All hypothesis tests were two-tailed where applicable, the significance level was set to alpha $=0.05$. All analyses were carried out with $\mathrm{R}$ software environment for statistical computing 3.4.4 [31].

\section{Results}

In our total primary sample $(n=2,511)$, diagnostic criteria for asthma were met by 208 children $(9.5 \%)$ of the study cohort, of which most cases were of male sex ( $n=$ $122,58.7 \%, p=0.019)$. In the total sample, 815 children (44.1\%) were prepubertal, $264(14.3 \%)$ were in pubertal group II, $161(8.7 \%)$ in III, 206 (11.1\%) in IV, and 406 (21.9\%) in V. Atopy status (42\% in controls vs. $77.7 \%$ in cases, $p<0.001)$ as well as family history for asthma $(9.8 \%$ in controls vs. $29.8 \%$ in cases, $p<0.001$ ) and pubertal status $(p<0.001)$ was highly correlated with asthma diagnoses (Table 1). Moreover, children without asthma were significantly older $(12.5$ vs. 10.9 years, $p<0.001)$ than children with asthma. After matching for atopy and age ( $n=471)$, these grouping factors were distributed equally, and, of note, sex and pubertal status of participants were 
Fig. 1. Flow chart of the study. * Exception for 4 cases with an age difference of 6.6, 7.7, 10.9 , and 12 months, respectively. ${ }^{+}$BMISDS, WC-SDS, NC-SDS, WHtR-SDS. BMI; body mass index; SDS, SD score; WHtR, waist-to-height ratio.

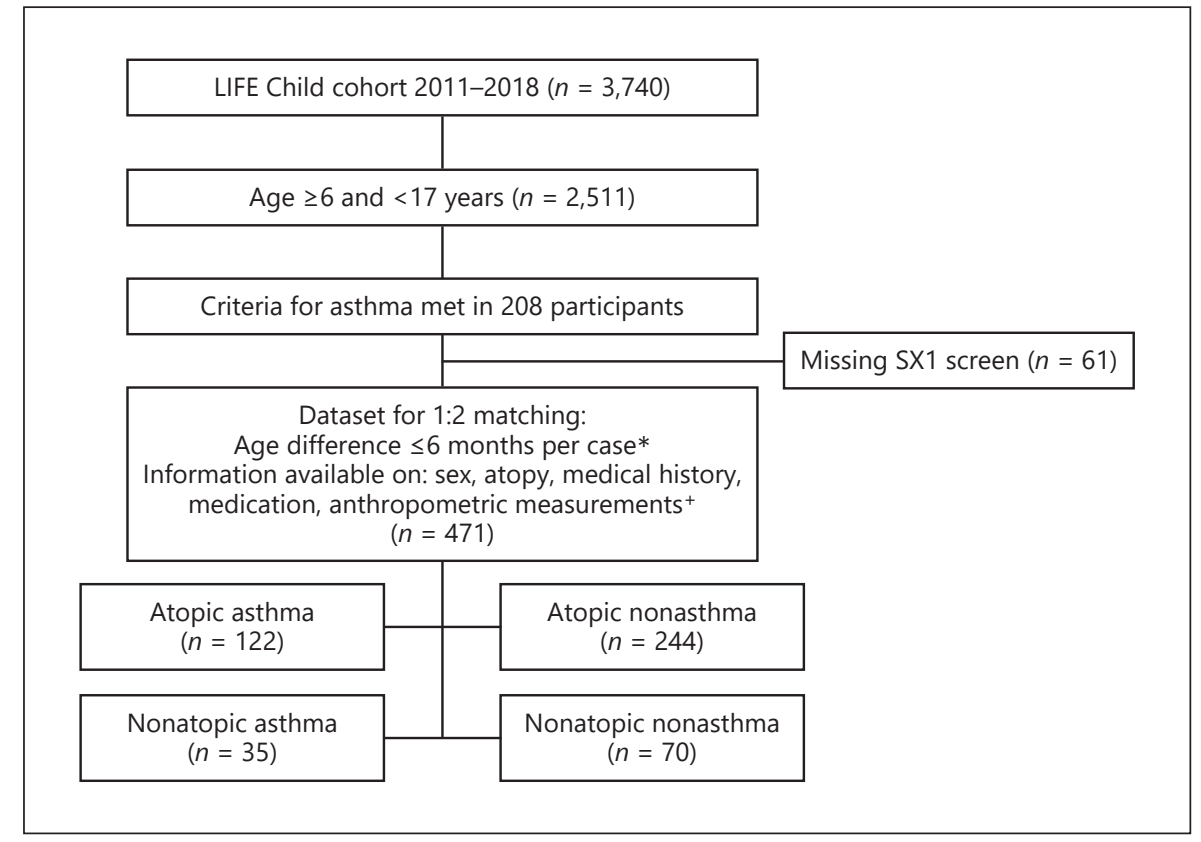

Table 3. Conditional logistic regression analyses for anthropometric measures of overweight and asthma, differentiated by atopy status

\begin{tabular}{|c|c|c|c|c|c|c|}
\hline & \multicolumn{3}{|c|}{ Atopic asthma } & \multicolumn{3}{|c|}{ Non-atopic asthma } \\
\hline & OR & $95 \%$ CI & $p$ value & OR & $95 \%$ CI & $p$ value \\
\hline BMI & 1.195 & $0.993-1.439$ & 0.06 & 0.879 & $0.6-1.285$ & 0.51 \\
\hline NC & 1.083 & $0.863-1.36$ & 0.49 & 0.819 & $0.545-1.232$ & 0.34 \\
\hline WC & 1.218 & $0.966-1.535$ & 0.096 & 0.95 & $0.613-1.47$ & 0.82 \\
\hline WHtR & 1.261 & $1.03-1.544$ & $0.025^{\star}$ & 0.9 & $0.592-1.369$ & 0.620 \\
\hline
\end{tabular}

Significant results are marked by asterisk.

BMI, body mass index; NC, neck circumference; $p$, significance level of $\alpha=0.05$; WC, waist circumference; WHtR, waist-to-height ratio; BMI, NC, $\mathrm{WC}$ and WHtR expressed in standard deviation scores (SDS).

no more differing significantly among cases and controls (Table 2).

A total of $1,728(75.1 \%)$ children of the total sample had a normal weight (BMI-SD score (SDS) $>-1.28$ and $<$ 1.28), 183 (7.9\%) had overweight (BMI-SDS $\geq 1.28-<$ $1.88)$, and $391(17 \%)$ had obesity (BMI-SDS $\geq 1.88)$ according to current national guidelines [32].

In univariate analyses in the primary sample, no significant associations were found of BMI-SDS, WHtRSDS, WC-SDS, and NC-SDS with asthma. This was consistent considering all weight status proxies as continuous parameters as well as weight groups defined by the cutoff values of the respective 90th or 97th percentile. Only WHtR-SDS showed a slight trend toward higher values in individuals with asthma compared to controls (WHtRSDS 0.42 vs. $0.27, p=0.076$; Table 1 ). Moreover, in the total sample, no group differences in the associations of overweight, atopy, and asthma were found when performing conditional logistic regression analyses controlled for gender.

As depicted in Table 3, conditional logistic regression in the matched control group revealed that in children with atopy, all overweight proxies were consistently positively associated with asthma. However, statistical significance was only reached for WHtR-SDS (OR 1.26, 95\% CI $1.03-1.54, p=0.025$ ), but the effect sizes were similar (but slightly smaller) for WC and BMI-SDS (Table 3). Without controlling for atopy status, no statistically significant association of overweight proxies and asthma was detectable neither (data not shown).

Positive atopy status was significantly associated with lower WHtR-SDS ( 0.15 vs. $0.47, p=0.01)$ in atopic, compared to nonatopic participants (CI of the difference $0.07-0.55)$ as depicted in Figure 2.

In both, in total and matched sample (except matched sample WHtR-SDS prepubertal 0.12 vs. pubertal 0.30, $p=$ 0.096), overweight proxies were significantly higher in pubertal than in prepubertal children. In our total sample, the rate of atopics among pubertal children was sig- 


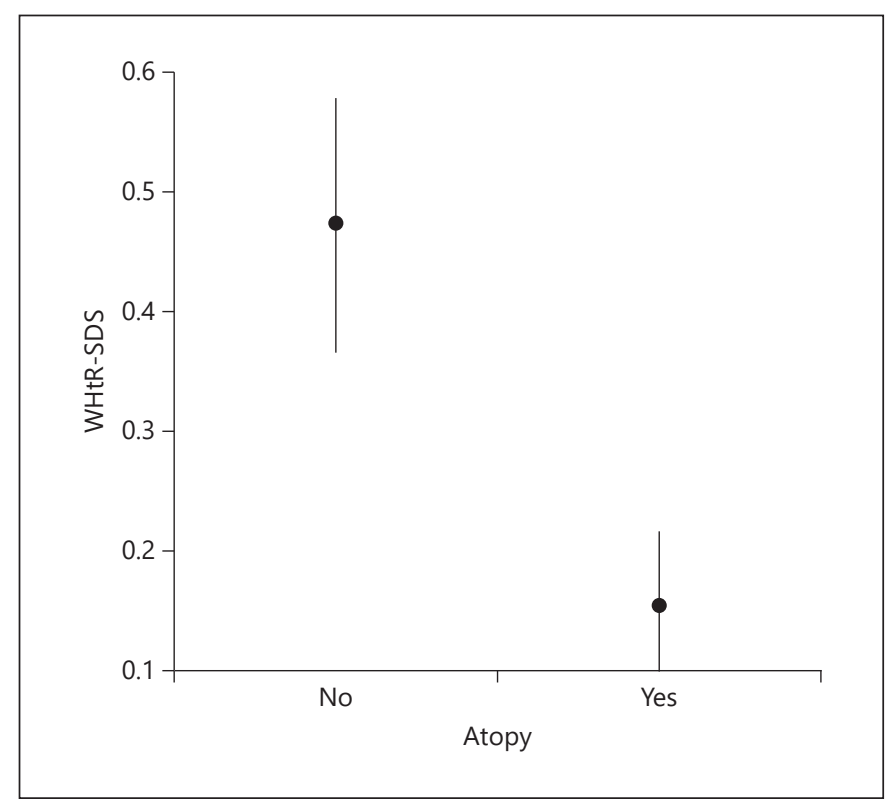

Fig. 2. Mean and SE of WHtR-SDS in atopic and nonatopic participants in the matched cohort. WHtR, waist-to-height ratio; SDS, SD score.

nificantly higher than in prepubertal children $(n=668$, $46.1 \%$ vs. $n=255,40 \% ; p=0.011$ ). In the age- and atopymatched sample, there was no significant difference of pubertal status (atopic pubertal children $79.2 \%$ vs. prepubertal atopic children 75.5\%; $p=0.405$ ).

We performed conditional logistic regressions of asthma and WHtR-SDS stratified by known influencing factors on asthma to assure the consistency of the respective effects across these strata (e.g., birthweight $\geq 2,500$ vs. $<2,500 \mathrm{~g}$ ) and the consistency of atopy as effect modifier (Table 4). Here, no known influencing factor altered the quality of association of WHtR-SDS and asthma in a relevant magnitude neither in atopic cases nor in nonatopic cases. The covariates (see methods) did not change direction (positive vs. negative) of the associations of asthma with anthropometric measurements (Table 5).

HsCRP was positively associated with BMI-SDS in both, atopic and nonatopic children $\left(\beta_{\text {atopic }}=0.47, p \leq\right.$ $0.001 ; \beta_{\text {nonatopic }}=0.49, p \leq 0.001$; Fig. 3 ). There was no significant difference in the association of hsCRP with BMI-SDS between atopic and nonatopic children $\left(\mathrm{p}_{\text {interaction }}=0.82\right)$. HsCRP was positively associated with WHtR-SDS in both atopic and nonatopic children $\left(\beta_{\text {atopic }}=0.54, p \leq 0.001 ; \beta_{\text {nonatopic }}=0.48, p \leq 0.001\right)$. There was no significant difference in the association of hsCRP with WHtR-SDS between atopic and nonatopic children

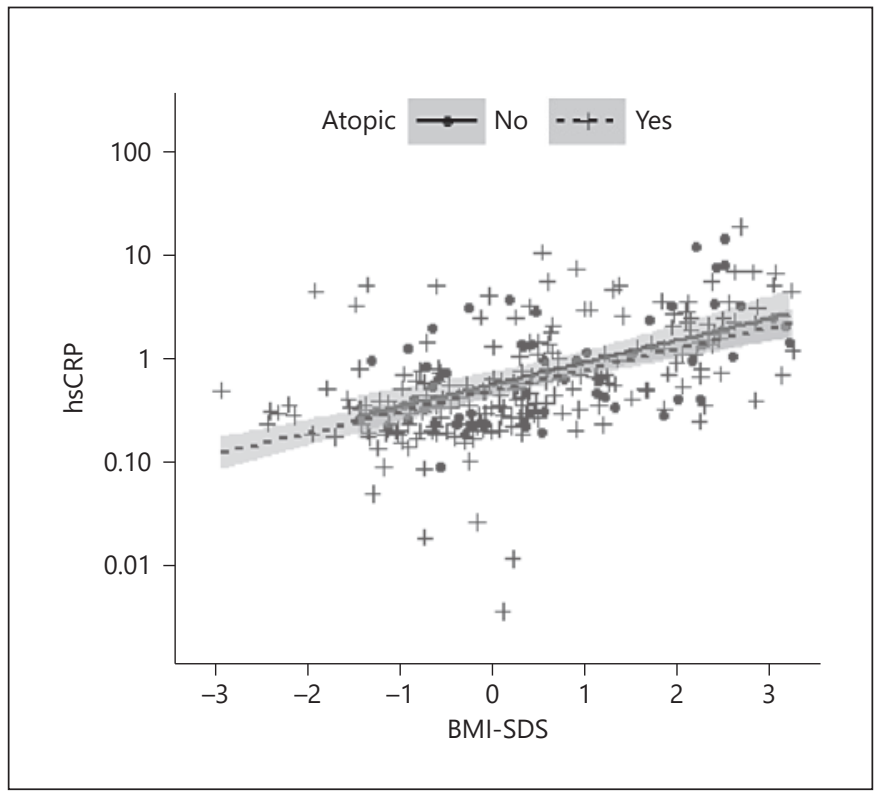

Fig. 3. Relation of hsCRP with atopy and BMI-SDS: BMI-SDS is positively correlated with hsCRP, but the groups of atopic and nonatopic study participants do not differ additionally. BMI; body mass index; SDS, SD score; hsCRP, high-sensitivity C-reactive protein.

Table 4. ORs with 95\% CIs for the associations between WHtR and asthma cases, differentiated between strata of participants with atopic versus nonatopic asthma by different covariates

\begin{tabular}{lll}
\hline $\begin{array}{l}\text { Association of WHtR: } \\
\text { asthma plus covariates }\end{array}$ & $\begin{array}{l}\text { Atopic asthma } \\
\text { OR }(95 \% \mathrm{CI})\end{array}$ & $\begin{array}{l}\text { Nonatopic asthma } \\
\text { OR }(95 \% \mathrm{CI})\end{array}$ \\
\hline $\begin{array}{l}\text { Winkler index middle } \\
\text { Sporting activity }\end{array}$ & $1.201(0.89-1.62)$ & $0.956(0.535-1.707)$ \\
$\quad$ Yes & $1.39(1.085-1.782)^{*}$ & $1.171(0.69-1.988)$ \\
$\quad$ No & $1.259(0.843-1.881)$ & $0.656(0.284-1.515)$ \\
No active smoking & $1.527(1.032-2.259)^{*}$ & $0.761(0.276-2.101)$ \\
No passive smoking & $1.066(0.712-1.595)$ & $0.959(0.351-2.624)$ \\
Birth weight $\geq 2,500$ g & $1.224(0.986-1.518)$ & - \\
Breastfeeding $\geq 6$ months & $1.464(1.061-2.019)^{*}$ & $0.778(0.403-1.502)$ \\
$\begin{array}{l}\text { Negative family history } \\
\text { Prepubertal children }\end{array}$ & $1.308(1.041-1.644)^{*}$ & $0.768(0.486-1.212)$ \\
\hline
\end{tabular}

Significant results are marked by asterisk.

WHtR, waist-to-height ratio; SD, SD score.

$\left(p_{\text {interaction }}=0.59\right)$. Similar results were found when investigating association of hsCRP with WC and NC. No significant association of IL- 6 with BMI-SDS $\left(\beta_{\text {atopic }}=0.04\right.$, $p=0.95 ; \beta_{\text {nonatopic }}=-0.18, p=0.67 ; p_{\text {interaction }}=0.17$; Fig. 4) was found, nor was such found when investigating its associations with WC, WHtR, and NC. 
Fig. 4. Relation of IL-6 with atopy and BMI-SDS: IL-6 is not significantly associated with BMI-SDS and the groups of atopic and nonatopic study participants do not differ additionally. IL-6, interleukin-6; BMI, body mass index; SDS, SD score.

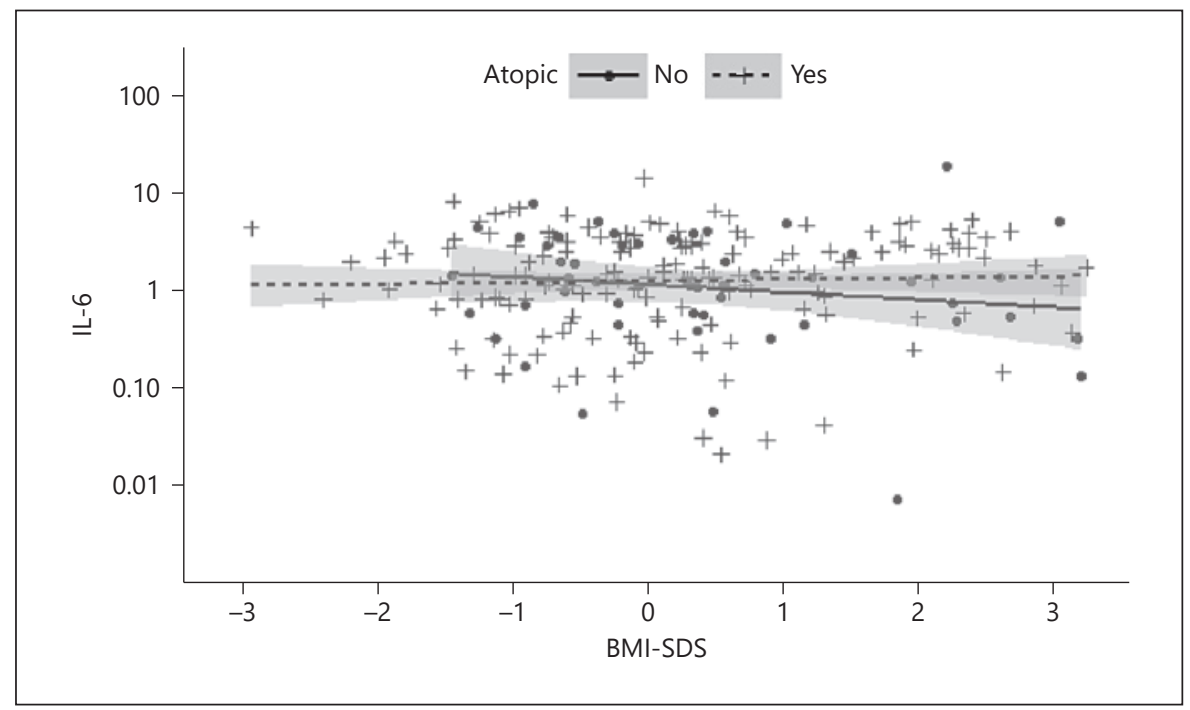

\section{Discussion}

Asthma prevalence in our cohort is higher compared to the prevalence $(6.3 \%)$ reported by a representative German cohort and may be due to differences in recruiting strategies [33, 34]. Increasing prevalence of atopic asthma and higher prevalence in male gender are in line with other studies [34, 35].

In our sample of children aged 6-16 years, we found that anthropometric overweight proxies were associated with asthma only in atopic children, when applying a matched case-control design mandating same age and atopy status of cases and controls. Thus, we cannot confirm the preponderant notion that overweight is associated with asthma in all children [4]. Importantly, in a 12 months longitudinal study, overweight in children was not associated with worse asthma severity, spirometry findings, quality of life, or health care utilization [36]. Hence, overweight's influence on asthma seems to stay disputed.

Associations were significant for WHtR only, but all anthropometric measures of obesity were in trend correlated positively with asthma in atopic children. Thus, results of studies that found positive associations between weight status and asthma might be mostly induced by an atopic subpopulation that was not further characterized as such $[4,12]$.

Regarding the effect of atopy on the association of overweight and asthma, our findings are in line with the work of Forno et al. [3] and a Swedish longitudinal study [37]. Both reported similar associations and a mediating effect of atopy on the relation of asthma and overweight where overweight might have a more deteriorating effect on asthma occurrence in atopic subjects. Accordingly, asthma control was worse in children with overweight when exhaled nitric oxide, a marker of eosinophilic inflammation, was elevated [38]. However, contradicting results from the "National Health and Nutrition Examination Survey" study showed positive associations of overweight defined as high BMI-SDS and asthma in nonatopic children earlier [10]. No associations between overweight and atopy were found in The International Study of Asthma and Allergies in Childhood Phase 2 study [39]. The discrepancies of results might have several reasons such as effect-modifying covariates. Age might be such a strong effect modifier. Therefore, strict age matching might be an efficient and effective way to eliminate age's influence because neither asthma onset [24] nor overweight onset increase linearly with age [40] and, therefore, a strict age matching may lead to less agebiased results.

We suggest that children with atopy may be more prone to a negative effect of weight gain and develop more asthma than nonatopics.

Our results suggest that overweight has a more increasing effect on the incidence of asthma in atopic than in nonatopic children.

Interestingly, NC showed least significant results. Thus, we could not replicate the findings of a Turkish cohort with $46 \%$ overweight children [2], where higher strata of NC above their local NC $>90$ th percentile were highly correlated with asthma. In this work by Akın et al. [2], 
Table 5. ORs with $95 \%$ CIs for the associations between anthropometric measurements and asthma and association with different covariates

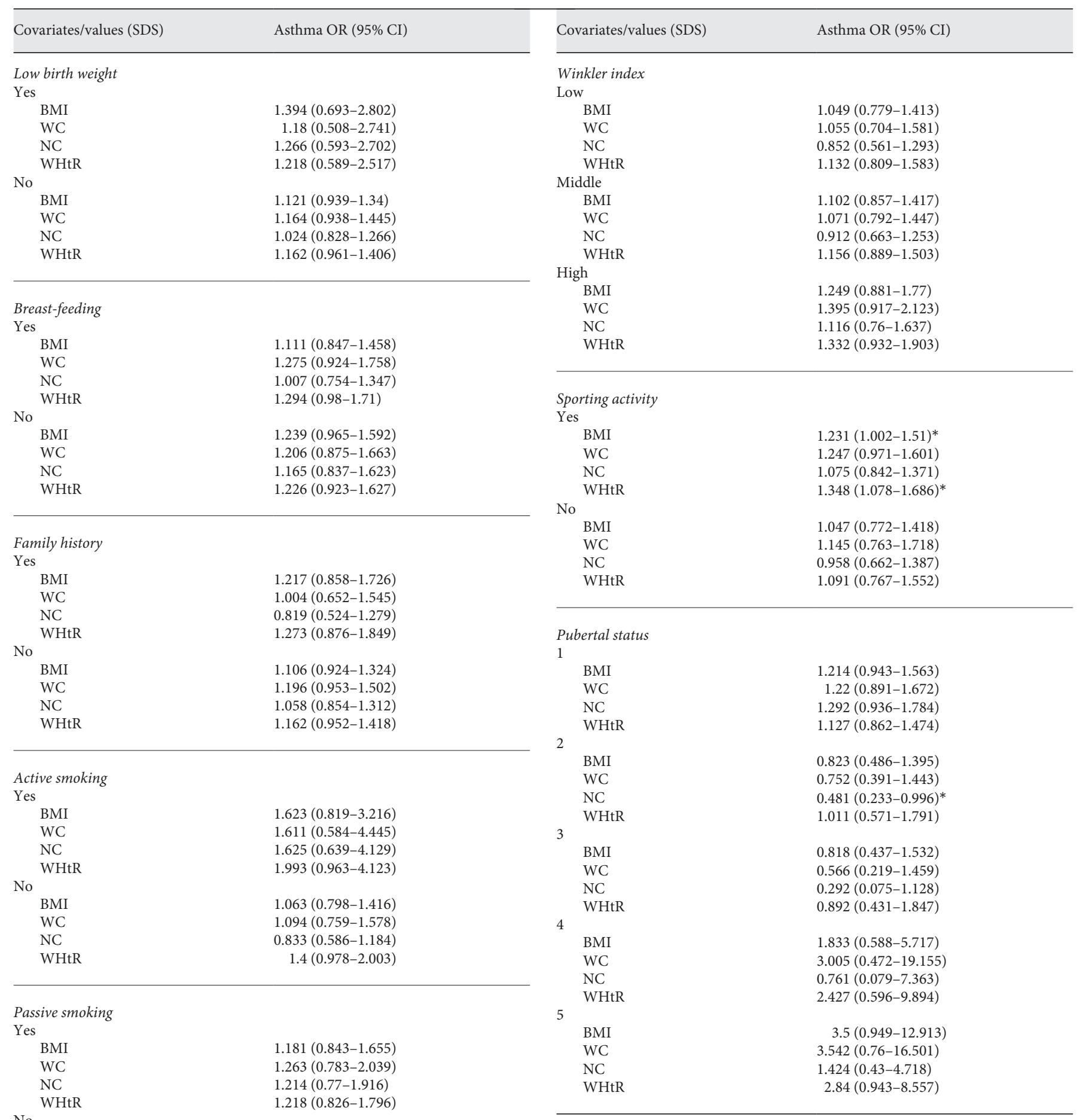

No

BMI $\quad 0.943(0.665-1.339)$

WC $\quad 0.845(0.541-1.322)$

NC $\quad 0.698(0.423-1.153)$

WHtR $1.051(0.724-1.528)$
Significant associations are marked by asterisk.

BMI, body mass index; NC, neck circumference; WC, waist circumference; WHtR, waist-to-height ratio; SDS, SD score. 
age differences of asthma cases (aged 7-12 years) were not controlled for. Our results as well as the work of Zhuang et al. [41], who documented a significant difference of BMI and NC in 18 vs. 29 year olds, stress the importance of controlling for age effects not only on asthma but also on anthropometric measurements that may account for differing results.

There is a vast body of scientific work on differential fat distribution and its effects on asthma or cardiovascular disease. In particular, WHtR was shown to be associated with higher cardiovascular mortality [42-44]. While we found WHtR to be significantly associated with asthma in atopic children, other studies identified BMI and WC [3] or waist-to-hip ratio [45] as the strongest predictor. Despite small differences in magnitude, National Health and Nutrition Examination Survey-based data revealed similar results of different anthropometric markers in the associations of obesity and asthma [11], like our study. Therefore, since no anthropometric measure is linked to fat cell mass directly [46], we suggest that measuring WC and WHtR, but not NC, may increase the chance of identifying children at risk for asthma when being atopic.

It was postulated that measuring BMI may be imprecise because of an influence of asthma therapy on the child's height [47], but current data point out that effect size of significant growth suppression of inhaled corticosteroids (ICS) is small [48]. Thus, the importance of this effect on BMI is disputed [48]. Like loss of growth potential, weight gain may be an effect of ICS. Here also, a meta-analysis of pediatric populations did not detect evidence for BMI change when using ICS [48]. In our study, data on duration of usage of ICS are not available; thus, we cannot entirely exclude treatment effects on BMI body composition of participants, which is a limitation. Given the little effect sizes, we think that enhanced security on asthma diagnosis by inclusion of current medication outweighs this possible flaw.

The underlying mechanism resulting in the observed association between overweight and atopy might be the link of inflammation and atopy. In children, mechanisms of proinflammatory effects of fat tissue were shown on a cellular level [49], and the potential role of inflammation as an effect modifier of the association between overweight and asthma is discussed at several occasions [50].

We were unable to detect differences in hsCRP in atopic versus nonatopic children with asthma when controlling for the effect of overweight in contrast to earlier works [51] that showed elevated serum CRP levels to be associated with increased asthma severity and overweight but did not control for atopy status. Likewise, in adults,
IL-6 had been shown to be associated with higher BMI, worse lung function [52-54], and more frequent asthma exacerbations leading to the suggestion of trials with IL-6 blocking agents in asthma therapy [53]. Moreover, neither a difference between atopic and nonatopic children nor a significant association with overweight was found for IL-6. Thus, our findings do not indicate more systemic inflammation in the group of atopic children with asthma, thus not explaining the effects of atopy here.

Interestingly, studies reviewing the role of IL-5 in adipose tissue suggest that fat tissue-specific eosinophils may exert specific effects, differing to eosinophils of other origins [55]. IL-4 and IL-5 were found to be elevated in subjects with central obesity [56]. Since IL-5-blockage effectively treats asthma in atopic individuals [57], our data support studying the eosinophil-adipocyte link rather than focusing on systemic inflammation derived from fat cells.

Some studies evaluated the influence of different covariates such as birth weight, breastfeeding, sporting activity, smoking, social status, and family history on the relation between overweight and asthma $[58,59]$.

If controlling univariately for these covariates, the positive association between overweight proxies and atopic asthma remained stable. It was, though, not possible to perform multivariate conditional logistic regression due to too low numbers of cases for several combinations of cofactors.

Our study revealed significantly higher overweight proxies in pubertal than in prepubertal children. Recently, it was suggested that in puberty increases the fat mass, which may increase systemic inflammation and therefore the risk to develop asthma symptoms [60]. Weight gain during childhood in overweight children [40] may contribute to a higher risk of atopy [60] and therefore to asthma symptoms. In contrast to Yoo et al. [60], our data does not suggest that the overweight - asthma link is associated with systemic inflammation.

Weaknesses of our analysis include its cross-sectional design and missing data on atopy status for $25 \%$ of participants. As a major strength, our work is the first study applying a matched case-control design to avoid agecaused biases regarding atopy, overweight, asthma occurrence, and their interrelations. Inclusion of objective measurements for atopy status rather than questionnaires may have excluded reporting bias due to changes in diagnostic habits and perception of disease as has been argued before [21].

It is well known that children with overweight more often complain about symptoms such as wheezing and more severe asthma than children with normal weight status $[39,61]$. Our data may suggest that subjective 
symptoms of dyspnea in children with overweight may be due to functional breathing difficulties and corresponding lung function impairment like solely reduced FEV1 [62] and not asthma with respect to variable airflow limitation and chronic inflammation hyperresponsiveness [1]. More studies with children on the starting point of their symptoms may be needed to better understand these relations.

Either way, for breathing impairment because of pure restriction of ventilation or asthma in the strict sense, prevention of overweight and weight reduction seems favorable given its positive effects on asthma symptoms and lung function parameters [63].

In conclusion, in observing associations between overweight and asthma only in atopic subjects, we challenge the concept of "obesity asthma" and call for more strict age matching in pediatric cohort studies and longitudinal studies for a better understanding for the causal links of overweight and atopy and asthma.

\section{Acknowledgments}

This publication is supported by LIFE - Leipzig Research Center for Civilization Diseases, Leipzig University and IFB AdiposityDiseases. We would like to thank all the children and their parents who participated and thank for the outstanding work of the study assistants.

\section{Statement of Ethics}

Written informed consent was obtained from the parents or guardians of all participants, and, from the age of 12 years, also from the participants themselves. The study protocol was approved by the Institutional Review Board of the Ethics Committee of the University of Leipzig (Registration Number 264-1019042010) following the principles of the Declaration of Helsinki.

\section{Disclosure Statement}

T.L. has received a speaking fee (Novartis) in 2018 with no influence on the present work.

\section{Funding Sources}

LIFE is funded by means of the European Union, by the European Regional Development Fund (ERDF), and by means of the Free State of Saxony within the framework of the excellence initiative. IFB AdiposityDiseases was supported by the Federal Ministry of Education and Research (BMBF), Germany, FKZ: 01EO1501.

\section{Author Contributions}

W.K., A.H., M.G., T.L., and A.K.: concept and design. All authors: acquisition and critical revision. M.G. and T.L.: drafting of the manuscript. M.V., M.G., and T.L.: statistical analyses. J.R.: laboratory supervision. W.K., M.V., and J.G.: supervision. A.H. and A.J.: administrative support. W.K. and A.K.: funding.

\section{References}

1 Global Initiative for Asthma. Global Strategy For Asthma Management And Prevention. [September 24, 2018]; Available from: www. ginasthma.org.

2 Akın O, Sarı E, Arslan M, Yeşilkaya E, Hacihamdioglu B, Yavuz ST. Association of wider neck circumference and asthma in obese children. Ann Allergy Asthma Immunol. 2016 Jun;116(6):514-7.

3 Forno E, Acosta-Pérez E, Brehm JM, Han YY, Alvarez M, Colón-Semidey A, et al. Obesity and adiposity indicators, asthma, and atopy in Puerto Rican children. J Allergy Clin Immunol. 2014 May;133(5):1308-14.

4 Egan KB, Ettinger AS, Bracken MB. Childhood body mass index and subsequent physician-diagnosed asthma: a systematic review and meta-analysis of prospective cohort studies. BMC Pediatr. 2013 Aug; 13(1):121.

5 Forno E. Childhood obesity and asthma: to $\mathrm{BMI}$ or not to BMI? J Allergy Clin Immunol. 2017 Mar; 139(3):767-8.

6 Fitzpatrick AM, Jackson DJ, Mauger DT, Boehmer SJ, Phipatanakul W, Sheehan WJ, et al.; NIH/NHLBI AsthmaNet. Individualized therapy for persistent asthma in young children. J Allergy Clin Immunol. 2016 Dec; 138(6):1608-1618.e12.

7 Lang JE, Fitzpatrick AM, Mauger DT, Guilbert TW, Jackson DJ, Lemanske RF Jr, et al.; National Institutes of Health/National Heart, Lung and Blood Institute AsthmaNet. Overweight/obesity status in preschool children associates with worse asthma but robust improvement on inhaled corticosteroids. J Allergy Clin Immunol. 2018 Apr;141(4):1459-1467.e2.

8 Longo C, Bartlett G, Schuster T, Ducharme FM, MacGibbon B, Barnett TA. The obeseasthma phenotype in children: an exacerbating situation? J Allergy Clin Immunol. 2018 Apr;141(4):1239-1249.e4.

9 Musaad SM, Patterson T, Ericksen M, Lindsey M, Dietrich K, Succop P, et al. Comparison of anthropometric measures of obesity in childhood allergic asthma: central obesity is most relevant. J Allergy Clin Immunol. 2009 Jun;123(6):1321-7.e12.

10 Visness CM, London SJ, Daniels JL, Kaufman JS, Yeatts KB, Siega-Riz AM, et al. Association of childhood obesity with atopic and non- atopic asthma: results from the National Health and Nutrition Examination Survey 1999-2006. J Asthma. 2010 Sep;47(7):822-9.

11 Forno E, Han YY, Libman IM, Muzumdar RH, Celedón JC. Adiposity and Asthma in a Nationwide Study of Children and Adults in the United States. Ann Am Thorac Soc. 2018 Mar;15(3):322-30.

12 Azizpour Y, Delpisheh A, Montazeri Z, Sayehmiri K, Darabi B. Effect of childhood BMI on asthma: a systematic review and meta-analysis of case-control studies. BMC Pediatr. 2018 Apr;18(1):143.

13 Peters U, Dixon AE, Forno E. Obesity and asthma. J Allergy Clin Immunol. 2018 Apr; 141(4):1169-79.

14 den Dekker HT, Ros KP, de Jongste JC, Reiss IK, Jaddoe VW, Duijts L. Body fat mass distribution and interrupter resistance, fractional exhaled nitric oxide, and asthma at school-age. J Allergy Clin Immunol. 2017 Mar;139(3):810-818.e6.

15 WHO Collaborating Centre for Drug Statistics Methodology. ATC/DDD Index 2018. [September 24, 2018]; Available from: https:// www.whocc.no/atc_ddd_index/. 
16 Cole TJ, Green PJ. Smoothing reference centile curves: the LMS method and penalized likelihood. Stat Med. 1992 Jul;11(10):1305-19.

17 Dathan-Stumpf A, Vogel M, Rieger K, Thiery J, Hiemisch A, Kiess W. Serum lipid levels were related to socio-demographic characteristics in a German population-based child cohort. Acta Paediatr. 2016 Aug;105(8):e360-7.

18 Rieger K, Vogel M, Engel C, Ceglarek U, Harms K, Wurst U, et al. Does physiological distribution of blood parameters in children depend on socioeconomic status? Results of a German cross-sectional study. BMJ Open. 2018 Mar;8(3):e019143.

19 Wabitsch M, Kunze D. Konsensbasierte (S2) Leitlinie zur Diagnostik, Therapie und Prävention von Übergewicht und Adipositas im Kindes- und Jugendalter.: Version 15.10 2015; www.a-g-a.de. 2015.

20 Peters SP. Asthma phenotypes: nonallergic (intrinsic) asthma. J Allergy Clin Immunol Pract. 2014 Nov-Dec;2(6):650-2.

21 Zöllner IK, Weiland SK, Piechotowski I, Gabrio T, von Mutius E, Link B, et al. No increase in the prevalence of asthma, allergies, and atopic sensitisation among children in Germany: 1992-2001. Thorax. 2005 Jul;60(7): 545-8.

22 Poulain T, Baber R, Vogel M, Pietzner D, Kirsten T, Jurkutat A, et al.; LIFE Child study team. The LIFE Child study: a populationbased perinatal and pediatric cohort in Germany. Eur J Epidemiol. 2017 Feb;32(2):14558.

23 Quante M, Hesse M, Döhnert M, Fuchs M, Hirsch C, Sergeyev E, et al.; LIFE Child Study Investigators. The LIFE child study: a life course approach to disease and health. BMC Public Health. 2012 Nov;12(50):1021.

24 Grabenhenrich LB, Gough H, Reich A, Eckers $\mathrm{N}$, Zepp F, Nitsche O, et al. Early-life determinants of asthma from birth to age 20 years: a German birth cohort study. J Allergy Clin Immunol. 2014 Apr;133(4):979-88.

25 Pinart M, Benet M, Annesi-Maesano I, von Berg A, Berdel D, Carlsen KC, et al. Comorbidity of eczema, rhinitis, and asthma in IgEsensitised and non-IgE-sensitised children in MeDALL: a population-based cohort study. Lancet Respir Med. 2014 Feb;2(2):131-40.

26 Weiland SK, Björkstén B, Brunekreef B Cookson WO, von Mutius E, Strachan DP; International Study of Asthma and Allergies in Childhood Phase II Study Group. Phase II of the International Study of Asthma and $\mathrm{Al}-$ lergies in Childhood (ISAAC II): rationale and methods. Eur Respir J. 2004 Sep;24(3): 406-12.

27 Ho DE, Imai K, King G, et al. MatchIt: Nonparametric Preprocessing for Parametric Causal Inference. [September 24, 2018]; Available from: https://r.iq.harvard.edu/ docs/matchit/2.4-20/matchit.pdf.

$28 \mathrm{Gu}$ XS, Rosenbaum PR. Comparison of Multivariate Matching Methods: Structures, Distances, and Algorithms. J Comput Graph Stat. 1993;2(4):405-20.
29 Winkler J, Stolzenberg H. Der Sozialschichtindex im Bundes-Gesundheitssurvey. Gesundheitswesen. 1999 Dec; 61(Spec No):S178-83.

30 Tanner JM. Growth and Development at Adolescence. In: Kracht J, editor. Endokrinologie der Entwicklung und Reifung. Symposion der Deutschen Gesellschaft für Endokrinologie in Ulm vom 26.-28. Februar 1970. Volume 16. Berlin, Heidelberg: Springer; 1970.

31 R Core Team. R: A language and environment for statistical computing. [September 24, 2018]; Available from: https://www.R-project. org/.

32 Kromeyer-Hauschild K, Wabitsch M, Kunze D, Geller F, Geiß HC, Hesse V, et al. Perzentile für den Body-mass-Index für das Kindes- und Jugendalter unter Heranziehung verschiedener deutscher Stichproben. Monatsschr Kinderheilkd. 2001;149(8):807-18.

33 Schlaud M, Atzpodien K, Thierfelder W. Allergische Erkrankungen. Ergebnisse aus dem Kinder- und Jugendgesundheitssurvey (KiGGS). Bundesgesundheitsblatt Gesundheitsforschung Gesundheitsschutz. 2007 May-Jun;50(5-6):701-10.

34 Schmitz R, Thamm M, Ellert U, Kalcklösch M, Schlaud M. Verbreitung häufiger Allergien bei Kindern und Jugendlichen in Deutschland. Ergebnisse der KiGGS-Studie Erste Folgebefragung (KiGGS Welle 1). Bundesgesundheitsbl. 2014;57(7):771-8.

35 Chen YC, Dong GH, Lin KC, Lee YL. Gender difference of childhood overweight and obesity in predicting the risk of incident asthma: a systematic review and meta-analysis. Obes Rev. 2013 Mar; 14(3):222-31.

36 Peters JI, McKinney JM, Smith B, Wood P, Forkner E, Galbreath AD. Impact of obesity in asthma: evidence from a large prospective disease management study. Ann Allergy Asthma Immunol. 2011 Jan;106(1):30-5.

37 Loid P, Goksör E, Alm B, Pettersson R, Möllborg P, Erdes L, et al. A persistently high body mass index increases the risk of atopic asthma at school age. Acta Paediatr. 2015 Jul;104(7): $707-12$.

38 Han YY, Forno E, Celedón JC. Adiposity, fractional exhaled nitric oxide, and asthma in U.S. children. Am J Respir Crit Care Med. 2014 Jul;190(1):32-9.

39 Weinmayr G, Forastiere F, Büchele G, Jaensch A, Strachan DP, Nagel G; ISAAC Phase Two Study Group. Overweight/obesity and respiratory and allergic disease in children: international study of asthma and allergies in childhood (ISAAC) phase two. PLoS One. 2014 Dec;9(12):e113996.

40 Geserick M, Vogel M, Gausche R, Lipek T, Spielau U, Keller E, et al. Acceleration of BMI in Early Childhood and Risk of Sustained Obesity. N Engl J Med. 2018 Oct;379(14): 1303-12.

41 Zhuang Z, Landsittel D, Benson S, Roberge R, Shaffer R. Facial anthropometric differences among gender, ethnicity, and age groups. Ann Occup Hyg. 2010 Jun;54(4):391-402.
42 Kahn HS, Imperatore G, Cheng YJ. A population-based comparison of BMI percentiles and waist-to-height ratio for identifying cardiovascular risk in youth. J Pediatr. 2005 Apr; 146(4):482-8.

43 Sardinha LB, Santos DA, Silva AM, Grøntved A, Andersen LB, Ekelund U. A Comparison between BMI, Waist Circumference, and Waist-To-Height Ratio for Identifying Cardio-Metabolic Risk in Children and Adolescents. PLoS One. 2016 Feb;11(2):e0149351.

44 Valle-Leal J, Abundis-Castro L, HernándezEscareño J, Flores-Rubio S. Índice cintura-estatura como indicador de riesgo metabólico en niños. Rev Chil Pediatr. 2016 May-Jun; 87(3): 180-5.

45 Chih AH, Chen YC, Tu YK, Huang KC, Chiu TY, Lee YL. Mediating pathways from central obesity to childhood asthma: a populationbased longitudinal study. Eur Respir J. 2016 Sep;48(3):748-57.

46 Duren DL, Sherwood RJ, Czerwinski SA, Lee M, Choh AC, Siervogel RM, et al. Body composition methods: comparisons and interpretation. J Diabetes Sci Technol. 2008 Nov;2(6): 1139-46.

47 Protudjer JL, Lundholm C, Bergström A, Kull I, Almqvist C. The influence of childhood asthma on puberty and height in Swedish adolescents. Pediatr Allergy Immunol. 2015 Aug;26(5):474-81.

48 Hui RWH. Inhaled corticosteroid-phobia and childhood asthma: Current understanding and management implications. Paediatr Respir Rev. Apr;pii:S1526-0542(19)30035-1.

49 Landgraf K, Rockstroh D, Wagner IV, Weise S, Tauscher R, Schwartze JT, et al. Evidence of early alterations in adipose tissue biology and function and its association with obesity-related inflammation and insulin resistance in children. Diabetes. 2015 Apr;64(4):1249-61.

50 Matos SM, Jesus SR, Saldiva SR, Prado MS, D'Innocenzo S, Assis AM, et al.; SCAALA (Social Change, Asthma and Allergy in Latin America) Study Group. Overweight, asthma symptoms, atopy and pulmonary function in children of 4-12 years of age: findings from the SCAALA cohort in Salvador, Bahia, Brazil. Public Health Nutr. 2011 Jul;14(7):12708.

51 Michelson PH, Williams LW, Benjamin DK, Barnato AE. Obesity, inflammation, and asthma severity in childhood: data from the $\mathrm{Na}-$ tional Health and Nutrition Examination Survey 2001-2004. Ann Allergy Asthma Immunol. 2009 Nov;103(5):381-5.

52 Ilmarinen P, Tuomisto LE, Niemelä O, Danielsson J, Haanpää J, Kankaanranta T, et al. Comorbidities and elevated IL-6 associate with negative outcome in adult-onset asthma. Eur Respir J. 2016 Oct;48(4):1052-62.

53 Peters MC, McGrath KW, Hawkins GA, Hastie AT, Levy BD, Israel E, et al.; National Heart, Lung, and Blood Institute Severe Asthma Research Program. Plasma interleukin-6 concentrations, metabolic dysfunction, and 
asthma severity: a cross-sectional analysis of two cohorts. Lancet Respir Med. 2016 Jul; 4(7):574-84.

54 Rincon M, Irvin CG. Role of IL-6 in asthma and other inflammatory pulmonary diseases. Int J Biol Sci. 2012;8(9):1281-90.

55 Bolus WR, Gutierrez D, Anderson-Baucum E, Kennedy A, Hasty A. The role of eosinophils in adipose tissue inflammation and metabolic function. J Immunol. 2017 May;198(1 Supplement):63.18.

56 El-Wakkad A, Hassan NM, Sibaii H, El-Zayat SR. Proinflammatory, anti-inflammatory cytokines and adiponkines in students with central obesity. Cytokine. 2013 Feb;61(2):682-7.
57 Haldar P, Brightling CE, Hargadon B, Gupta S, Monteiro W, Sousa A, et al. Mepolizumab and exacerbations of refractory eosinophilic asthma. N Engl J Med. 2009 Mar;360(10): 973-84.

58 Liu PC, Kieckhefer GM, Gau BS. A systematic review of the association between obesity and asthma in children. J Adv Nurs. 2013 Jul; 69(7):1446-65.

59 Papoutsakis C, Priftis KN, Drakouli M, Prifti S, Konstantaki E, Chondronikola M, et al. Childhood overweight/obesity and asthma: is there a link? A systematic review of recent epidemiologic evidence. J Acad Nutr Diet. 2013 Jan;113(1):77-105.

60 Yoo S, Kim HB, Lee SY, Kim BS, Kim JH, Yu $\mathrm{JH}$, et al. Association between obesity and the prevalence of allergic diseases, atopy, and bronchial hyperresponsiveness in Korean adolescents. Int Arch Allergy Immunol. 2011; 154(1):42-8.
61 Hacihamdioglu B, Arslan M, Yeşilkaya E, Gok F, Yavuz ST. Wider neck circumference is related to severe asthma in children. Pediatr Allergy Immunol. 2015 Aug;26(5):456-60.

62 Wang R, Custovic A, Simpson A, Belgrave DC, Lowe LA, Murray CS. Differing associations of BMI and body fat with asthma and lung function in children. Pediatr Pulmonol. 2014 Nov;49(11):1049-57.

63 Willeboordse M, van de Kant KD, Tan FE, Mulkens S, Schellings J, Crijns Y, et al. A Multifactorial Weight Reduction Programme for Children with Overweight and Asthma: A Randomized Controlled Trial. PLoS One. 2016 Jun;11(6):e0157158. 